\title{
Green Synthesis and Characterization of Silver Nanoparticles Using Pterocarpus marsupium and Assessment of its In vitro Antidiabetic Activity
}

\section{J Bagyalakshmi* and H Haritha}

Date of Receipt- 01-09-2017
Date of Revision- 20-09-2017

Date of Acceptance- 28-09-2017

\section{Address for}

Correspondence

Sri Ramakrishna Institute of paramedical sciences, College of Pharmacy, Coimbatore, India

E-mail: bagi_972003@yahoo.co.in

\section{ABSTRACT}

Objective: Green synthesis of silver nanoparticles from aqueous extract of Pterocarpus marsupium bark and wood and its characterization. As well as in vitro anti diabetic study was carried out.

Method: Synthesis of Pterocarpus marsupium silver nanoparticles was done by drop wise addition of $1 \mathrm{mM}$ silver nitrate to Pterocarpus marsupium bark and wood extract. Characterization of synthesized nanoparticles was carried out by visual examination, UV- Visible absorption spectroscopy, FTIR spectroscopy, Poly dispersity index and Zeta value. In vitro anti diabetic study for the synthesised silver nanoparticles was carried out by $\alpha$ - amylase inhibition assay.

Results: The synthesis of silver nanoparticles using Pterocarpus marsupium extract was eco-friendly and cost effective. Aqueous extract of Pterocarpus marsupium bark and wood extract were mixed with the aqueous solution of silver nitrate. The colour of the solution changes from yellow to brown colour due to the surface Plasmon resonance which is the primary confirmation for the formation of silver nanoparticles. The surface Plasmon band in the silver nanoparticles was found to be $431 \mathrm{~nm}$. The FTIR study concluded that hydroxyl and carboxyl groups act as reducing and stabilizing agent and phenolic group function as capping agent. Average particle size was found to be $148.5 \mathrm{~nm}$. It's polydispersity index was 0.336 and zeta potential was measured and found to be $-28 \mathrm{mV}$ with the peak area of $100 \%$ intensity. This indicates that formed nanoparticles were stable. The in vitro anti diabetic study confirms that Pterocarpus marsupium is having anti diabetic activity

Conclusion: Pterocarpus marsupium silver nanoparticles are found to be effective for anti-diabetic activity. The study found without using any chemical reagent as stabilizing agent the silver nanoparticles are stable. Hence this cost effective and eco-friendly method is highly promising for future.

Keywords: Pterocarpus marsupium, Silver nanoparticles, Anti diabetic, Green synthesis.

\section{INTRODUCTION}

Growth of nanoparticles has a great footprint in recent years. There is increasing optimism that nanotechnology, as applied to medicine, will bring significant advances in the diagnosis and treatment of disease. Working with these extremely small structures is very much interesting due to its unique properties. Nanoparticles can be defined as sub nano sized colloidal structures with particles size between 1 and 100 nanometres $(\mathrm{nm})^{1}$.

Silver nanoparticles (AgNPs) are widely used due to their unique physical and chemical properties in various fields such as medical, food, health care, consumer, and industrial purposes. These include optical, electrical, and thermal, high electrical conductivity, and biological 
properties. Due to their peculiar properties, they have been used for several applications. Syntheses of silver nanoparticles are carried out using three methods physical, chemical, and biological methods.

Biological methods have emerged to overcome all the problems related to physical and chemical methods. Silver nanoparticles are synthesised with definite size using different biological systems including bacteria, fungi, plant extracts, and small bio molecules like vitamins and amino acids as an alternative method to chemical methods not only for AgNPs, but also for the synthesis of several other nanoparticles ${ }^{2}$. The plant extract has been used in the production of silver nanoparticles had drawn attention due to its rapid, eco-friendly, non-pathogenic and providing a single step technique for the biosynthetic processes.

The bio molecules present in the plant extract such as proteins, aminoacids, enzyme, polysaccharides, alkaloids, tannins, phenolics, saponins, terpenoids, and vitamins are responsible for reduction and stabilization of silver ions.

Herbal medicine has a long history to treat diseases Medicinal plants are very useful in a number of ways in combating diseases. In the last few years there has been an exponential growth in the use of herbal drugs. Many traditional medicines in use are derived from medicinal plants, minerals and organic matter. Herbs are also effective in prevention and treatment of the toxicity induced by other drugs or toxins. Certain bioactive substances, flavanoids, antioxidants and phenolic substances are rich in medicinal plants which are regarded as a vital source in developing drugs for variety of diseases like Type II diabetes Mellitus, cancer, atherosclerosis and cardiovascular diseases. These medicinal plants are also used for the treatment of various infectious diseases ${ }^{3}$. According to World Health Organization (WHO) there are about 21,000 plants, which are used for medicinal purposes around the world. Among these 2500 species are found in India. India is called as botanical garden of the world because of the rich herbal medicine resources. Very recently, two exhaustive reviews have been published based on global literature survey on 150 plants and 343 plants from different parts of the world. Some plants like Allium cepa (Onion, piyaj), Allium sativum (garlic, lasun), Syzygiumcumini (Syn. Eugenia jambolana; (black plum; jamun), Momordicacharantia (bitter gaurd) Gymemasylvestre (Gurmar), Pterocarpusmarsupium (Vijaysar) etc. are well noticed by scientists as well as laymen, in recent years.
Pterocarpus marsupium is a medicinal plant widely distributed in India. Pterocarpus marupium is also known as Indian kino, Bijasal, Vijaysar, belongs to the family Leguminosae. PM is grown in central, western and southern regions of india. The heart wood leaves; flowers and bark have useful medicial properties ${ }^{4}$. The plant is traditionally used for various diseases like diabetics, angina, cancer, and used as cardiotonic, brain tonic ${ }^{5}$.

Hypoglycaemic activity of Pterocarpus marsupium bark and wood is popular in traditional medicine. Many studies were conducted with Pterocarpus marsupium for diabetic activity and found the following effects:

- Beta cell regeneration

- Inhibition of amylase and glucosidase

- Reduce TNF- $\alpha$

- Increase peroxisome proliferator activator receptors

- Insulin release

- Antiglycation effects ${ }^{6}$

In this study we synthesized silver nanoparticles using bark and wood extract of Pterocarpus marsupium and its characterization is done along with its in vitro anti diabetic study.

\section{MATERIALS}

\section{Chemical Reagents}

Silver nitrate $\left(\mathrm{AgNO}_{3}\right)$, Distilled water.

\section{Instruments Required}

Magnetic stirrer with hot plate, Magnetic bead, centrifuge (REMI), Shimadzu UV-visible spectrophotometer, IR spectrophotometer, Malvern Zeta size analyser, scanning electron microscopy.

\section{PROCEDURE}

\section{Sample Collection}

Pterocarpus marsupium bark and wood were collected from Palakkad, Kerala.Then it was cleaned properly with water.

\section{Authentication}

The plant specimen was identified and authenticated by Botanical survey of India, Southern regional centre, Coimbatore.

\section{Drying and Pulverizing}

The bark and wood were collected and shade dried at temperature not exceeding $400^{\circ} \mathrm{C}$. It was grounded 
into fine coarse powder with mixer. Then it was passed through sieve number 60 and kept in a well closed container in a dry place.

\section{Preparation of Aqueous Extract of Pterocarpus Marsupium}

Aqueous extract of Pterocarpus marsupium was prepared by cold maceration method. The air-dried coarse powder $(50 \mathrm{~g})$ of Pterocarpus marsupium accurately weighed and macerated with $500 \mathrm{ml}$ of solvent that is distilled water.And then allowed to stand for $24 \mathrm{hrs}$ and filtered rapidly with muslin cloth. The filtrate was evaporated to dryness at a temperature not exceeding $400^{\circ} \mathrm{C}$ for 2 hours.

\section{Phytochemical Screening}

Preparation of test solution: The filtered aqueous extract of Pterocarpus marsupium was used as a test solution for preliminary screening of phytochemical constituents.

Preliminary qualitative phytochemical analysis:

- Test for Alkaloids

Dragendorff's Reagent: To the test solution 1 $\mathrm{ml}$ of dragendroff's reagent (potassium bismuth iodide solution) was added.

Wagner's Reagent: To the test solution $1 \mathrm{ml}$ of Wagner's reagent (Iodine potassium iodide solution) was added.

Hager's Reagent: To the test solution add Hager's reagent (saturated solution of picric acid).

Tannic Acid Test: To the test solutions add Tannic acid solution.

- Test for Amino Acids

Millon's Test: To the test solutions add $2 \mathrm{ml}$ of Millon's reagent.

- Test for Carbohydrates

Molisch's Test: To the test solution add few drops of alcoholic a-naphthol, then add few drops of concentrated sulphuric acid through sides of test tube.

- Test for Flavonoids

Alkaline Reagent Test: To the test solution add few drops of sodium hydroxide solution, and then add few drops of dilute acid.

Legal's Test: Treat the test solution with pyridine and add alkaline sodium nitroprusside solution.
Baljet's Test: Treat the test solution with picric acid or sodium picrate, orange colour formed indicates the presence of glycosides.

- $\quad$ Test for Tannins (Phenolic Compounds)

Ferric chloride Test: Treat the extract with few drops of ferric chloride.

Test for Chlorogenic Acid: Treat the test solution with aqueous ammonia and expose to air

- Test for Starch

To the aqueous extract add weak aqueous Iodine solution.

- Test for Proteins

Warming Test: Heat the test solution in a boiling water bath.

- Test for Steroids

Salkowski Test: Treat the extract with few drops of concentrated sulphuric acid?

Preparation of Stock Solution: $1 \mathrm{mg}$ of aqueous extract was weighed and diluted to $10 \mathrm{ml}$ with distilled water.

Preparation of $1 \mathrm{~mm}$ Silver Nitrate Aqueous Solution: $0.017 \mathrm{~g}$ of silver nitrate was dissolved in $100 \mathrm{ml}$ of distilled water and stored in amber coloured bottle until further use ${ }^{8}$.

Synthesis of Pterocarpus Marsupium silver nanoparticles: $5 \mathrm{ml}$ Pterocarpus marsupium aqueous extract was taken in a beaker and paced on a magnetic stirrer with hot plate. To this $50 \mathrm{ml}$ of $1 \mathrm{Mm}$ silver nitrate solution was added drop wise with constant stirring $120 \mathrm{rpm}$ at $50-600^{\circ} \mathrm{C}$. The colour change of the solution was checked periodically. The colour change of the solution from yellow to brown colour indicates the formation of silver nanoparticles ${ }^{8}$.

Separation of silver nanoparticles: The synthesised Pterocarpus marsupium silver nanoparticles were separated by centrifugation using REMI centrifuge at $5000 \mathrm{rpm}$ for 15 minutes. The supernatant liquid was discarded and the pellets were collected stored ${ }^{8}$.

Preformulation Study- UV Spectroscopy

Preparation of calibration curve of Pterocarpus marsupium bark and wood extract using $U V$ visible absorption spectroscopy with phosphate buffer at pH 7.4: $10 \mathrm{mg}$ of Pterocarpus marsupium extract was dissolved in $10 \mathrm{ml}$ phosphate buffer at $\mathrm{pH} 7.4$ to give a concentration of $1 \mathrm{mg} / \mathrm{ml}$. From this solution 
$2.5 \mathrm{ml}$ was diluted with $25 \mathrm{ml}$ of phosphate buffer. Further dilutions are made to get the concentration (4-20 $\mu \mathrm{g} / \mathrm{ml})$. Then absorbance of each solution was measured at $279 \mathrm{~nm}$ using phosphate buffer as blank (Figures 1 and 2).

UV Vis spectral analysis of Pterocarpus marsupium wood and bark: $0.5 \mathrm{ml}$ of Pterocarpus marsupium wood extract and $0.5 \mathrm{ml}$ of bark extract were taken in a $10 \mathrm{ml}$ standard flask and diluted with distilled water and then UV-visible spectra were taken in the range of 200-400 $\mathrm{nm}$ using phosphate buffer at $\mathrm{pH}$ 7.4 as blank.

\section{Fourier Transform Infrared Spectroscopy [FTIR]}

FTIR spectroscopy of Pterocarpus marsupium wood and bark: $50 \mathrm{mg}$ each of dried Pterocarpus marsupium bark and wood was mixed with $100 \mathrm{mg}$ of spectral grade $\mathrm{KBr}$ and pressed into disc under hydraulic pressure. Then FTIR spectra were recorded in the $4000-400 \mathrm{~cm}^{-1}$ range (Figure 3$)^{10}$.

FTIR spectroscopy of Pterocarpus marsupium silver nitrate: $100 \mathrm{mg}$ of Silver nitrate was mixed with $100 \mathrm{mg}$ of spectral grade $\mathrm{KBr}$ and pressed into disc under hydraulic pressure. Then FTIR spectra were recorded in the $4000-400 \mathrm{~cm}^{-1}$ range (Figure 4) ${ }^{10}$.

Characterization of synthesized Pterocarpus marsupium silver nanoparticles: Characterization of Pterocarpus marsupium silver nanoparticles was carried out using the following parameters.

- Colour change: The primary confirmation of the synthesised PM silver nanoparticles is done by visual basis. The colour change of Pterocarpus marsupium extract and silver nitrate solution with respect to time was observed ${ }^{11}$.

- UV visible spectroscopy: UV visible spectral analysis characterizes the formation and completion of PM silver nanoparticles. The reduction of silver ions were monitored by measuring UV-Vis spectrum of reaction medium from the wavelength of $200-800 \mathrm{~nm}$ by using distilled water as blank. Periodic sampling at time intervals of $30 \mathrm{~min}, 60 \mathrm{~min}, 90 \mathrm{~min}, 120$ min, and $26 \mathrm{~h}$ was carried out 9 .

- Fourier Transform Infrared Spectroscopy: Dried samples (PM silver nanoparticles) of about 100 $\mathrm{mg}$ were mixed with $100 \mathrm{mg}$ of spectral grade $\mathrm{KBr}$ and pressed into discs under hydraulic pressure. FTIR spectra were recorded in the range $4000-400 \mathrm{~cm}^{-1}$. FTIR measurements were carried out to identify the bio molecules responsible for capping and stabilization of metal nanoparticles synthesised $^{11}$.

Determination of particle size: The dried powders of Pterocarpus marsupium silver nanoparticles dispersed in water to obtain proper scattering intensity of Pterocarpus marsupium silver nanoparticles. The particle size was determined by Malvern zeta size analyser $^{12}$.

Determination of zeta potential: The zeta potential was measured by using Zeta Sizer (Malvern Instruments) having zeta cells, polycarbonate cell with gold-plated electrodes and using water as medium for sample preparation. Zeta potential determines the surface potential of silver nanoparticles and it is essential for the characterization of stability of nanoparticles ${ }^{12}$.

\section{In vitro Anti Diabetic Study}

A-amylase inhibition assay: From $1 \mathrm{mg} / \mathrm{ml}$ stock solution different concentrations of plant extracts were prepared in phosphate buffer. $500 \mu 1$ of test/ standard was added to $500 \mu \mathrm{l}$ of $\alpha$ - amylase $(0.5 \mathrm{mg} / \mathrm{ml})$ was incubated for 10 minutes at room temperature. Then added $500 \mu \mathrm{l}$ of $1 \%$ starch solution and incubated for another 10 minutes. After that $1 \mathrm{ml}$ of colouring reagent was added to reaction mixture and heated in boiling water bath for 15 minutes after cooling, $10 \mathrm{ml}$ of distilled water was added. To measure absorbance of the coloured extracts blank was prepared for each set of concentration of test sample by replacing the enzyme with buffer. Control incubations representing $100 \%$ enzyme activity was prepared by replacing test drug with buffer. Absorbance measured at $540 \mathrm{~nm}^{13}$.

Inhibition activity $(\%)=\frac{A b s(\text { control })-A b s(\text { extract })}{A b s(\text { control })}$

Positive control: Acarbose is an anti-diabetic drug used to treat Type-2 diabetes mellitus. It was used as a positive control.

The IC50 values (inhibitor concentration at which $50 \%$ inhibition of the enzyme activity occurs) of the PM extracts were determined by performing the assay as above with varying concentrations of extracts ranging from $100^{-1}-600 \mu \mathrm{g} / \mathrm{ml}$ and standard drug Acarbose from $100^{-1}-600 \mu \mathrm{g} / \mathrm{ml}$. The IC50 values were determined from plot of percent inhibition versus inhibitor concentration by linear regression analysis $^{14}$.

\section{RESULTS AND DISCUSSION}

\section{Preformulation Study}

Construction of standard curve: In the standard curve, linearity was obtained between the 
concentrations of $4-20 \mu \mathrm{g} / \mathrm{ml}$ and the regression value was found to be $\mathrm{r} 2=0.999$ hence it obeys the Beer Lambert's Law. Table 1 gives the concentration versus absorbance values and Figure 1 shows the linearity of standard curve.

UV Visible Spectral Analysis of Pterocarpus Marsupium Wood and Bark

UV Visible spectra of Pterocarpus marsupium were taken in the range of 200-800 $\mathrm{nm}$. The absorption peak were obtained at $279 \mathrm{~nm}$.

FTIR spectroscopy of Pterocarpus marsupium bark and wood: In the Pterocarpus marsupium bark and wood FTIR spectrum strong absorption peaks at 3693.01 and 3413 indicates $\mathrm{OH}$ stretching due to the presence of alcohol and phenol. Peaks at 1619.91 and 1530.24 indicates $\mathrm{C}=\mathrm{C}$ stretching of $\alpha$, $\beta$, unsaturated ketone and $\mathrm{N}-\mathrm{O}$ stretching of nitro compounds absorption peaks at 1384.64, 821.527 and 786.815 and 727.996 indicates the presence of alkanes, alkenes, and aromatic rings ${ }^{15}$.

FTIR spectroscopy of silver nitrate: In the FTIR spectrum of silver nitrate strong absorption peaks at $3648.66,3446.17,2925.48$ were resulted from the $\mathrm{OH}$ groups due to the presence of alcohols and phenols and strong absorption peak at $1541.81 \mathrm{~m}$ was resulted from stretching of $\mathrm{N}-\mathrm{O}$ (nitro compounds) ${ }^{10,15}$.

\section{Characterization}

Visual examination: Initial colour of Pterocarpus marsupium extract was yellow and it turns to dark brown colour after the addition of silver nitrate solution. Beyond 90 minutes there is no significant change in colour indicating the completion of the reduction reaction. The change in colour of the reaction mixture after 2 hours indicates the formation of AgNPs. This formation indicates that silver ions in reaction medium have been converted to elemental silver having the size of nanometric range (Figures 5-7).

UV visible spectral analysis: UV Visible spectral analysis characterizes the formation and completion of silver nanoparticles. The reduction of silver ions was monitored by measuring UV-Vis spectrum of reaction medium from the wavelength of $200-800 \mathrm{~nm}$ by using distilled water as blank. Periodic sampling at the time interval of $30 \mathrm{~min}, 90 \mathrm{~min}, 210 \mathrm{~min}$ and $24 \mathrm{hr}$ was carried out.

The reduction of $\mathrm{Ag}^{+}$to $\mathrm{Ag}^{0}$ via the active bio molecules present in the bark and wood extract of Pterocarpus marsupium was indicated by a colour change from yellow to brown colour. Silver nanoparticles exhibit Plasmon absorption band in the visible region. The metal nanoparticles have free electrons which gives the surface Plasmon resonance absorption band due to the combined vibrations of electrons of metal nanoparticles in resonance with light wave.

Silver nanoparticles are known to exhibit UV-Visible absorption in the range of 400-500 $\mathrm{nm}$. The sharp absorption bands of Pterocarpus marsupium silver nanoparticles were observed around $431 \mathrm{~nm}$.

FTIR spectroscopy: FTIR measurements were carried out to identify the biomolecules responsible for capping and stabilization of metal nanoparticles synthesised. The IR spectrum of Pterocarpus marsupium silver nanoparticles, Pterocarpus marsupium wood and bark mixed as well as for separate spectra for both bark and wood spectra were taken.

FTIR spectra of Pterocarpus marsupium silver nanoparticles: In the FTIR spectra of silver nanoparticles band between 3700-3584 corresponds to $\mathrm{OH}$ stretching of free alcohol, 3550- 3200 corresponds to hydrogen bonded alcohols and phenols, 2830-2695 corresponds to $\mathrm{CH}$ stretching in aldehyde, $1720^{-1} 706 \mathrm{C}=\mathrm{O}$ stretching in carboxylic acid, $1550^{-1} 500$ corresponds to nitro compounds (Figure 8) ${ }^{10,15}$.

From the FTIR spectral analysis it is concluded that hydroxyl and carboxyl groups present may act as reducing and stabilizing agent and phenolic group present may act as capping agent.

Particle size measurement: The particle size is one of the most important parameter for characterization nanoparticles. The average particle size of Pterocarpus marsupium was found to be $148.5 \mathrm{~nm}$. Particle size analysis showed the presence of nanoparticles with polydispersity indices PDI value 0.336 with intercept 0.963 (Figure 9).

Zeta potential measurement: Zeta potential is a key indicator for determining the stability of aqueous silver nanoparticles. For Pterocarpus marsupium silver nanoparticles zeta potential measured was found to be $-28 \mathrm{mV}$ with peak area of $100 \%$ intensity. These values indicate the full stabilization of nanoparticles (Figure 10) ${ }^{16}$.

\section{In vitro Antidiabetic Study}

$\alpha$ - amylase inhibition assay: $\alpha$-amylase is a key enzyme in carbohydrate metabolism. Inhibition of 
$\alpha$-amylase is one of the strategies for treating diabetes. Amylase inhibitors are also known as starch blockers because they contain substances that prevent dietary starches from being absorbed by the body. Amylase inhibitor with starchy meal will reduce the usual rise in blood sugar levels.

The result suggests that Pterocarpus marsupium exhibits good $\alpha$ - amylase inhibition under in vitro conditions (Tables 2 and 3 ).

The IC50 value of positive control was found to be $180 \mu \mathrm{g} / \mathrm{ml}$ and that of biosynthesised Pterocarpus marsupium silver nanoparticles were $700 \mu \mathrm{g} / \mathrm{ml}$. The percentage inhibition of Acarbose and Pterocarpus marsupium silver nanoparticles at lower and higher concentration was found to be $41.44 \%$ and $84.09 \%$ for positive control Acarbose and $21.88 \%$ and $71.14 \%$ respectively (Figures 11 and 12 ).

\section{CONCLUSION}

Pterocarpus marsupium silver nanoparticles are found to be effective for anti-diabetic activity. The study found without using any chemical reagent as stabilizing agent the silver nanoparticles are stable. Hence, this cost effective and eco-friendly method is highly promising for future.

\section{REFERENCES}

1. Vyas SP, Khar RK. Targeted and controlled drug delivery novel carrier systems. 2002;331-379.

2. Zhang XF. Silver nanoparticles: Synthesis, characterization, properties, applications, and therapeutic approaches. Int $\mathrm{J}$ Mol Sci. 2016;17:1534.

3. Perera HKI. Antidiabetic effects of Pterocarpus marsupium. Euro J Med P1. 2016;13(4):1-14.

4. Rajesham VV, Ravindernath A, Bikshapathi DVRN. A review on medicinal plants and herbal drug formulations used in diabetes mellitus. Int Am J Pharm Res. 2012;2(10):1200-12.

5. Tiwari M. Chemical constituents and medicinal uses of Pterocarpus marsupium roxb: Flora and fauna. Int J Drug Del Res. 2015;21:55-9.
6. Prathap BC. Pterocarpus marsupium Roxb: Apotent herb for life threatening diseases. Int $\mathrm{J}$ Res Phyt Pharm. 2012;2(2):75-83.

7. John PP. Pharmacognostical characterization of an anti-diabetic polyherbal formulation. Int $\mathrm{J}$ Drug Del Res. 2015;7(1):201-10.

8. Kokate CK, Purohit AP, Gokhale SB. Pharmacognostical and Physicochemical Standardization of Leaves of Spathodea Campanulata P. Beauv Pharmacognosy. 2009;1:1-6.

9. Aruna A. Synthesis and characterization of silver nanoparticles of insulin plant (costus pictus $\mathrm{d}$. don) leaves. Asian J Bio Pharma Sci. 2014;4(34):1-6.

10.Sikarwar MS. Preparation, characterization and evaluation of marsupsin-phospholipid complex. American Association of Pharmaceutical Scientists. 2008;9:129-37.

11. Holler S, Skoog C. Principles instrumental analysis. 6th ed. Chemzone. 2016;459-61.

12.Johnson I, Prabu HJ. Green synthesis and characterization of silver nanoparticles by leaf extracts of cyas circinals, ficus amplissima, commelina benghalensis and lippie nodiflora. International Nanoparticles Letters. 2015;43-51.

13. Vitthal KU, Pillai MM, Kininge P. Study of solid lipid nanoparticles as a carrier for bacoside. Int $\mathrm{J}$ Pharm Biol Sci. 2013;3:414-26.

14. Sivashanmugam G. Antioxidant \& antidiabetic activities of Pohyalthia longifolia with special emphasis on its possible role in diabetic complications. Int Sch Res Notices. 2017;170.

15.Dhivya G, Rajasimman M. Synthesis of silver nanoparticles using Momordica charantia and its applications. J Chem Pharm Res. 2015;7(9):10713.

16.Silverstein RM. Spectrometric identification of organic compounds. 6th ed. Federal Science. 2005;79-99. 
Table 1. Calibration curve of Pterocarpus marsupium bark and wood extract using UV- visible absorption spectroscopy at $279 \mathrm{~nm}$

\section{Concentration $(\mu \mathrm{g} / \mathrm{ml})$}

\begin{tabular}{|c|c|}
\hline Concentration $(\boldsymbol{\mu g} / \mathbf{m l})$ & Absorbance \\
\hline 4 & 0.0313 \\
\hline 8 & 0.0517 \\
\hline 12 & 0.0713 \\
\hline 16 & 0.0912 \\
\hline 20 & 0.112 \\
\hline
\end{tabular}

Table 2. $\alpha$-amylase inhibitory effects of acarbose

\section{Concentration $(\mu \mathrm{g} / \mathrm{ml})$}

50
100
200
400
800

\section{Absorbance}

0.832

0.703

0.625

0.426

0.226
Percentage Inhibition

$41.44 \%$

$50.52 \%$

$56.01 \%$

$70.02 \%$

$84.09 \%$

Table 3. $\alpha$-amylase inhibitory effects of Pterocarpus marsupium

\begin{tabular}{|c|c|c|}
\hline Concentration $(\boldsymbol{\mu g} / \mathbf{m l})$ & Absorbance & Percentage Inhibition \\
\hline 100 & 1.110 & $21.88 \%$ \\
\hline 200 & 0.951 & $33.07 \%$ \\
\hline 400 & 0.642 & $54.82 \%$ \\
\hline 100 & 0.531 & $62.63 \%$ \\
\hline
\end{tabular}




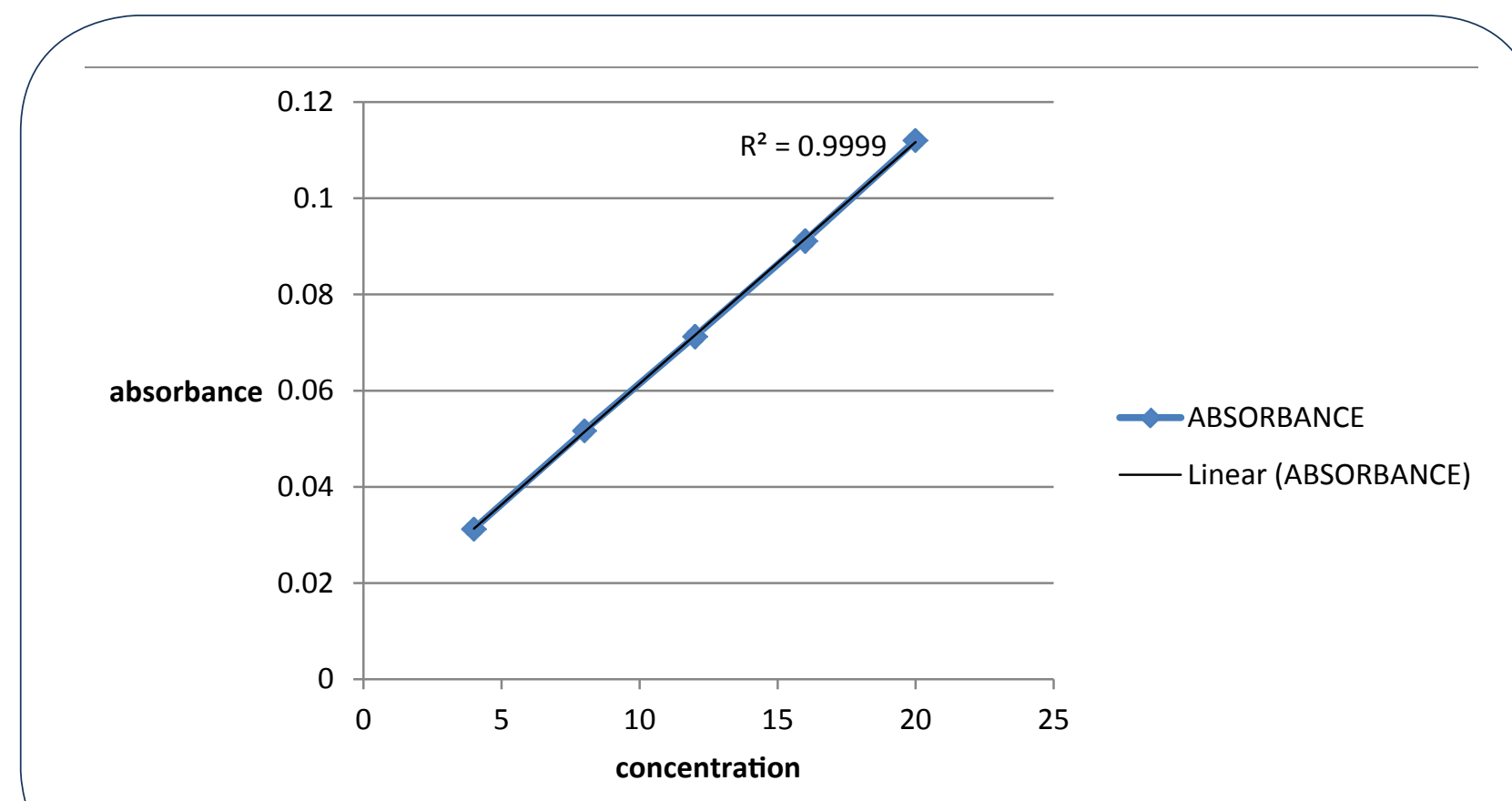

Figure 1. Calibration curve of Pterocarpus marsupium bark and wood extract and its regression value

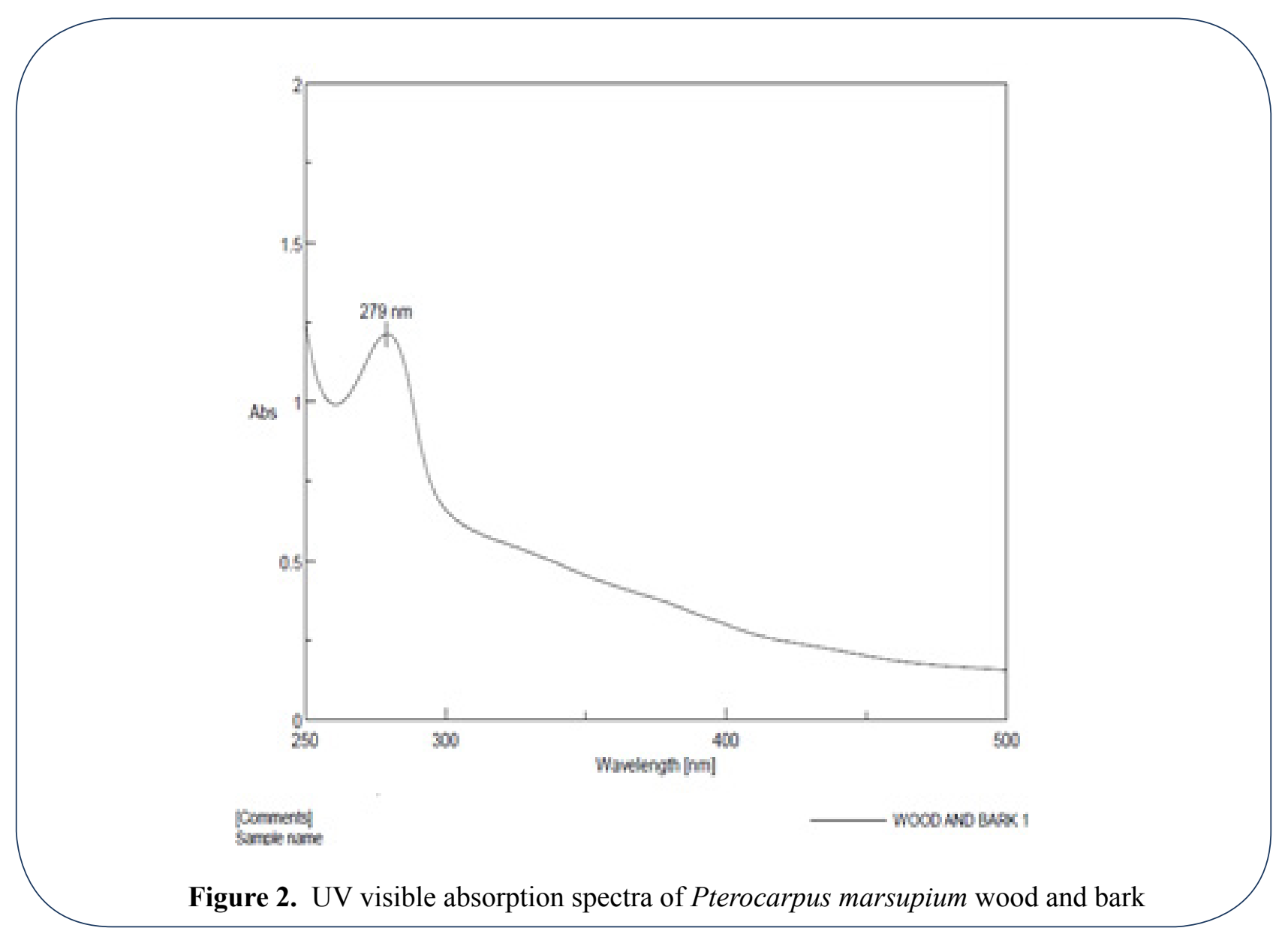




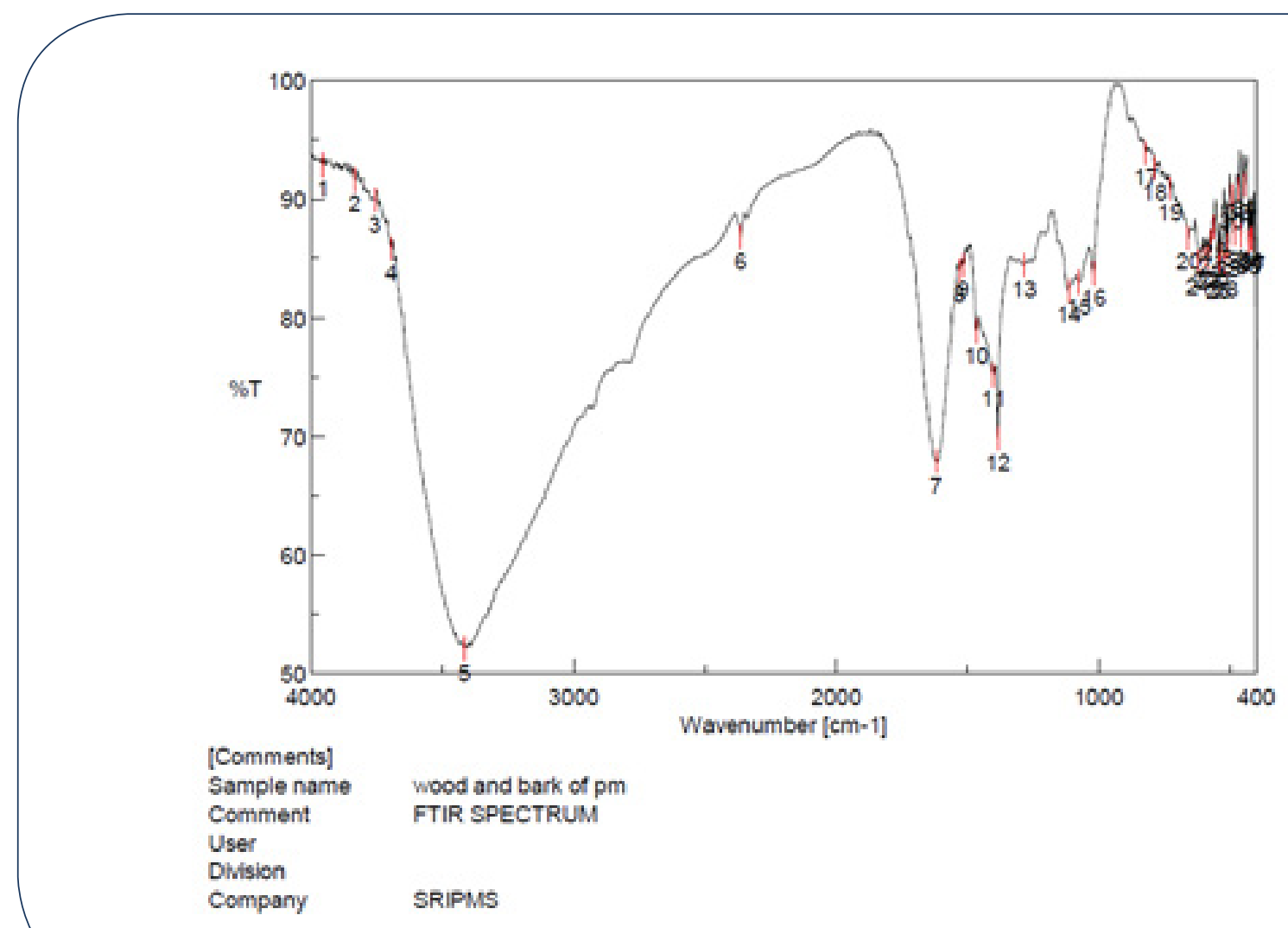

Figure 3. FTIR spectra of Pterocarpus marsupium wood and bark

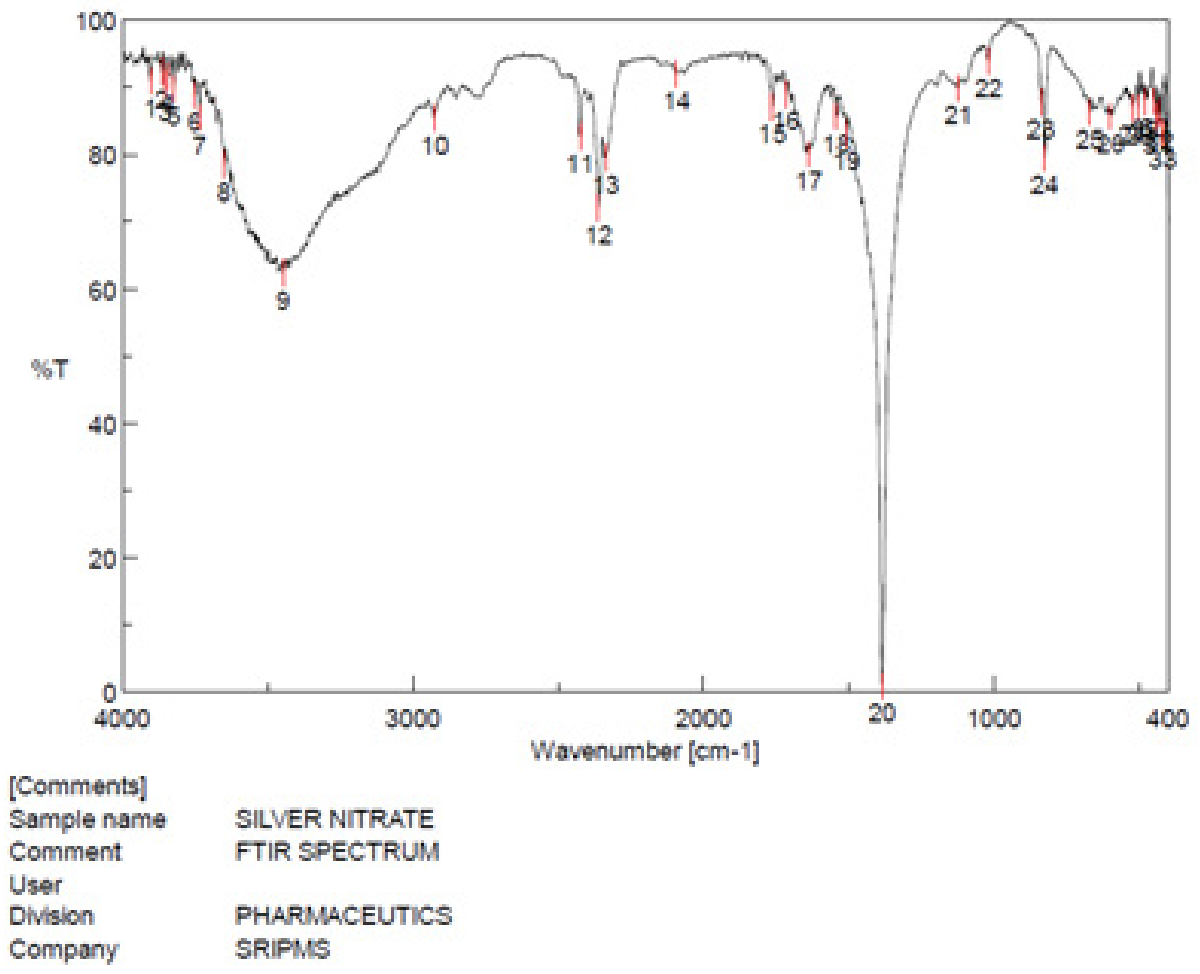

Figure 4. FTIR spectrum of silver nitrate 


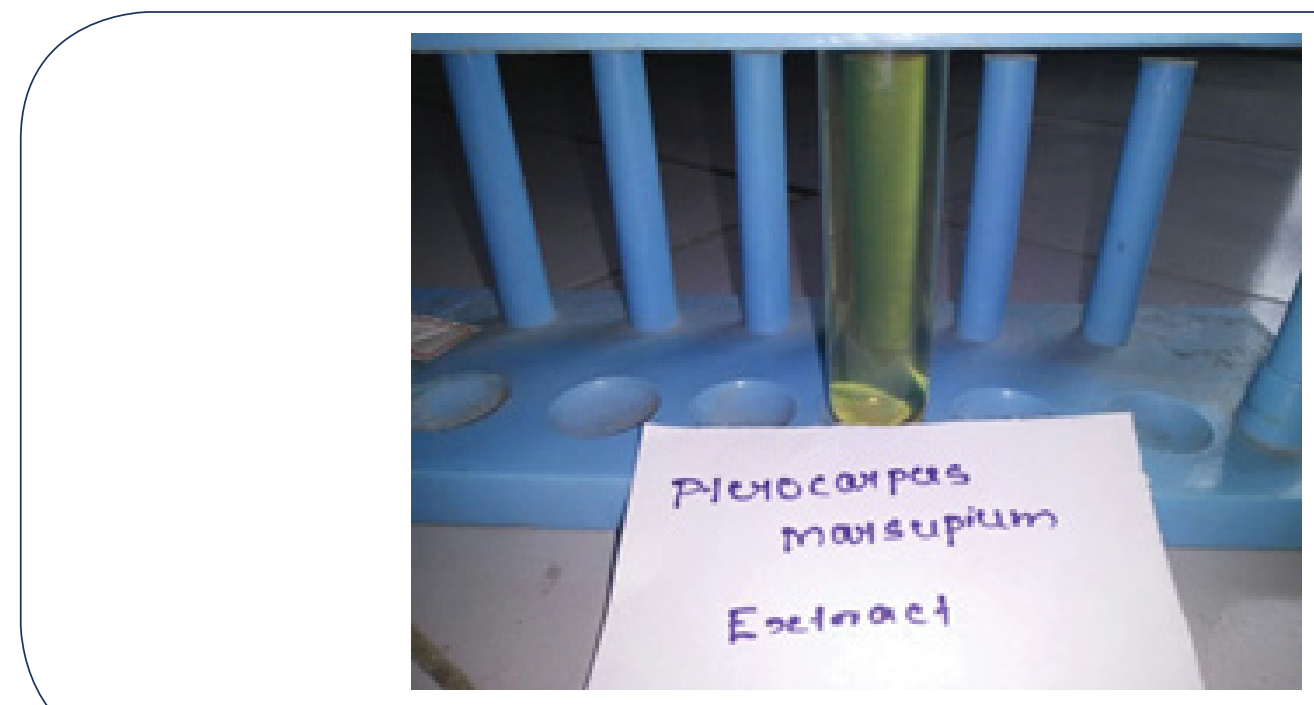

Figure 5. Pterocarpus marsupium extract

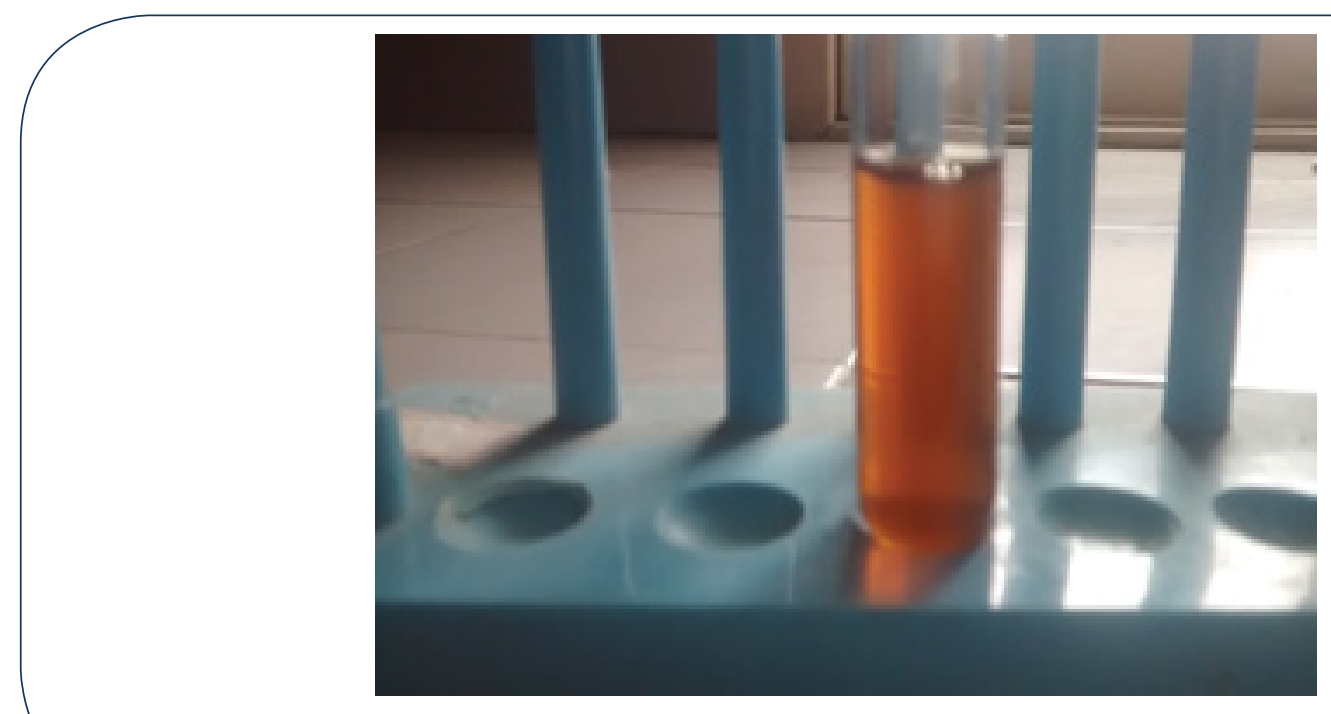

Figure 6. Pterocarpus marsupium extract turns to dark brown colour after the adding silver nitrate solution

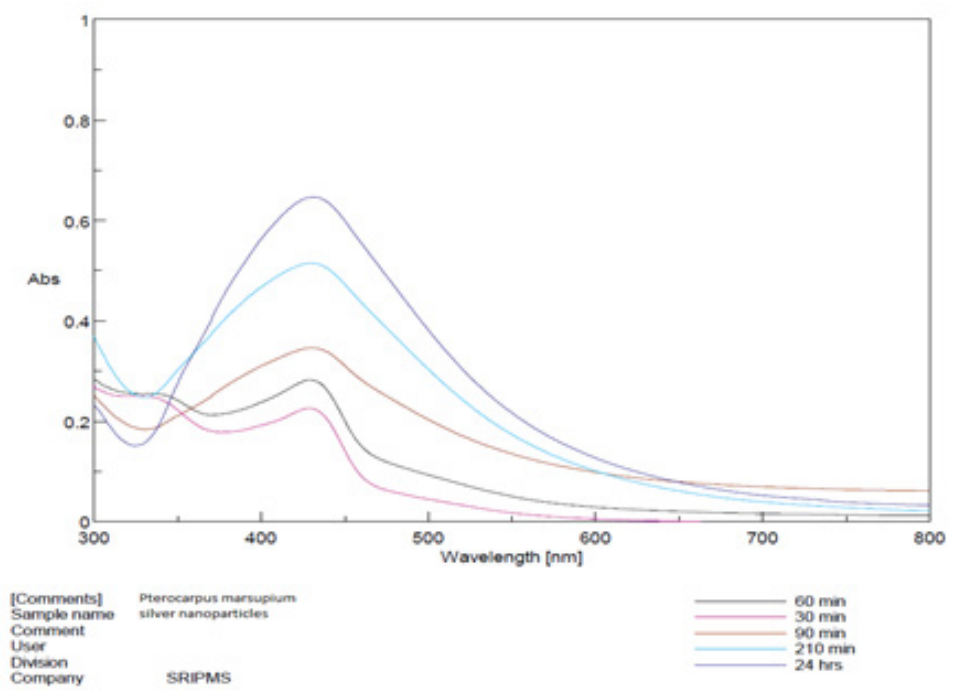

Figure 7. UV visible absorption spectra of Pterocarpus marsupium silver nanoparticles at different time intervals 


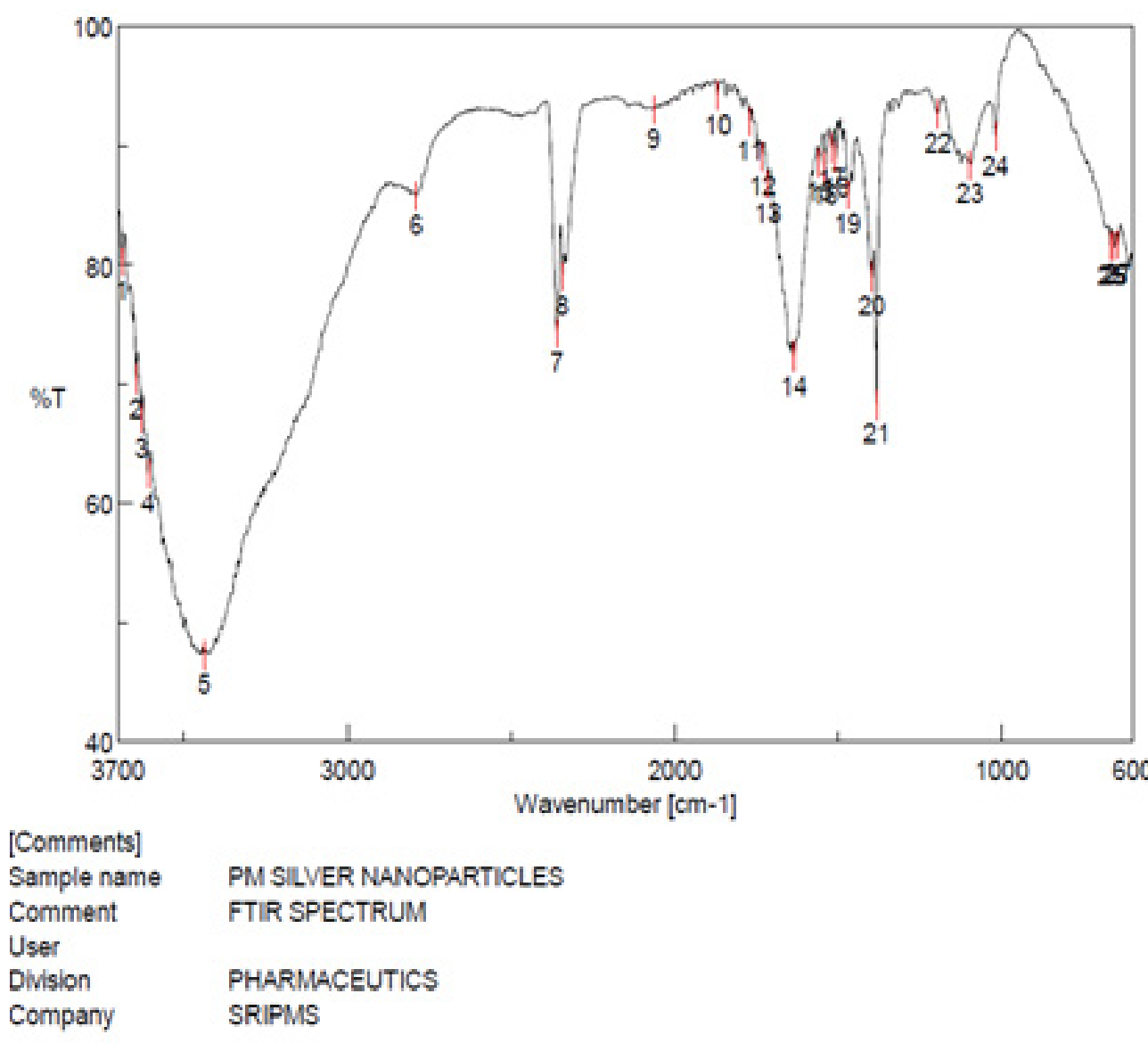

Figure 8. FTIR spectra of Pterocarpus marsupium silver nanoparticles

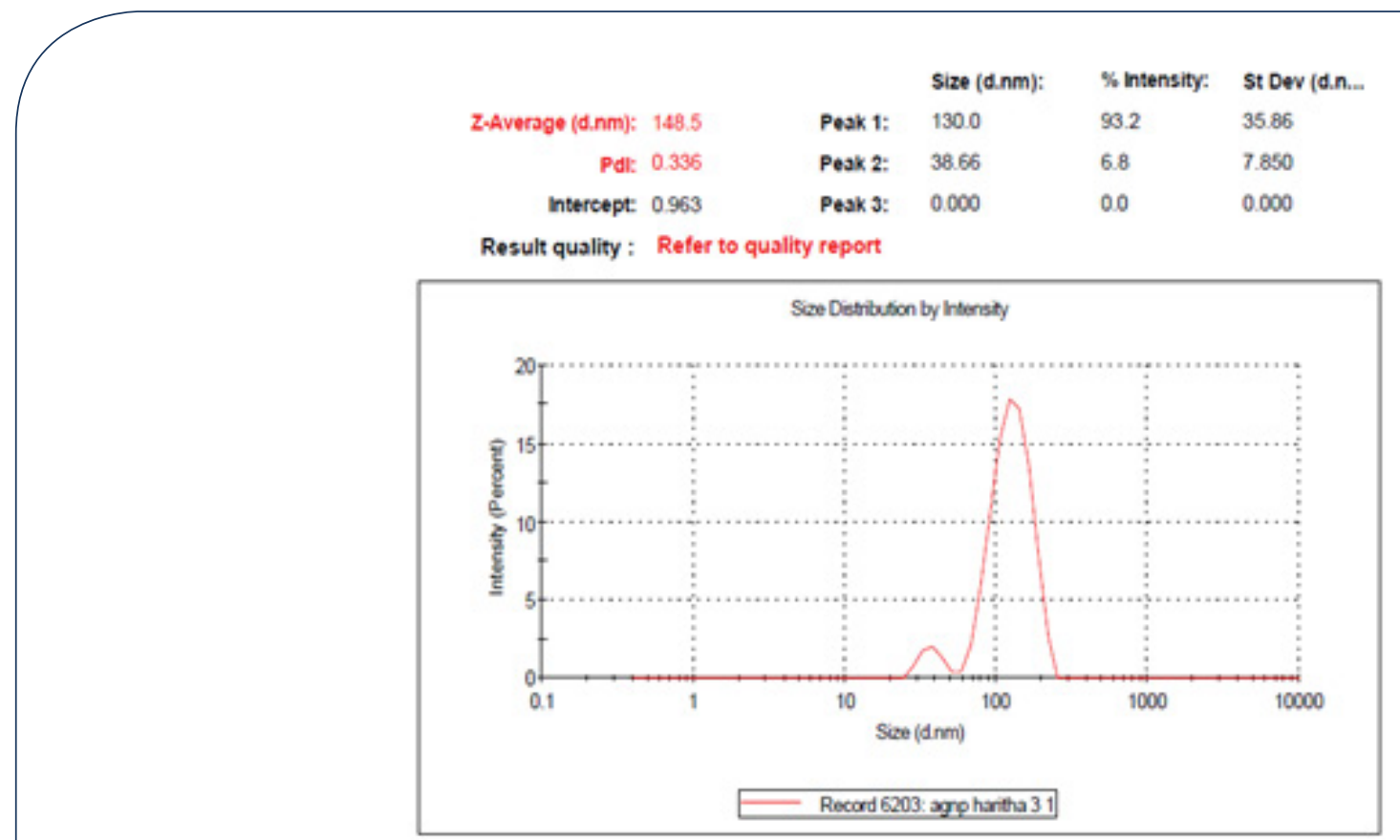

Figure 9. Percentage intensity of particle size distribution of biosynthesised Pterocarpus marsupium silver nanoparticles 


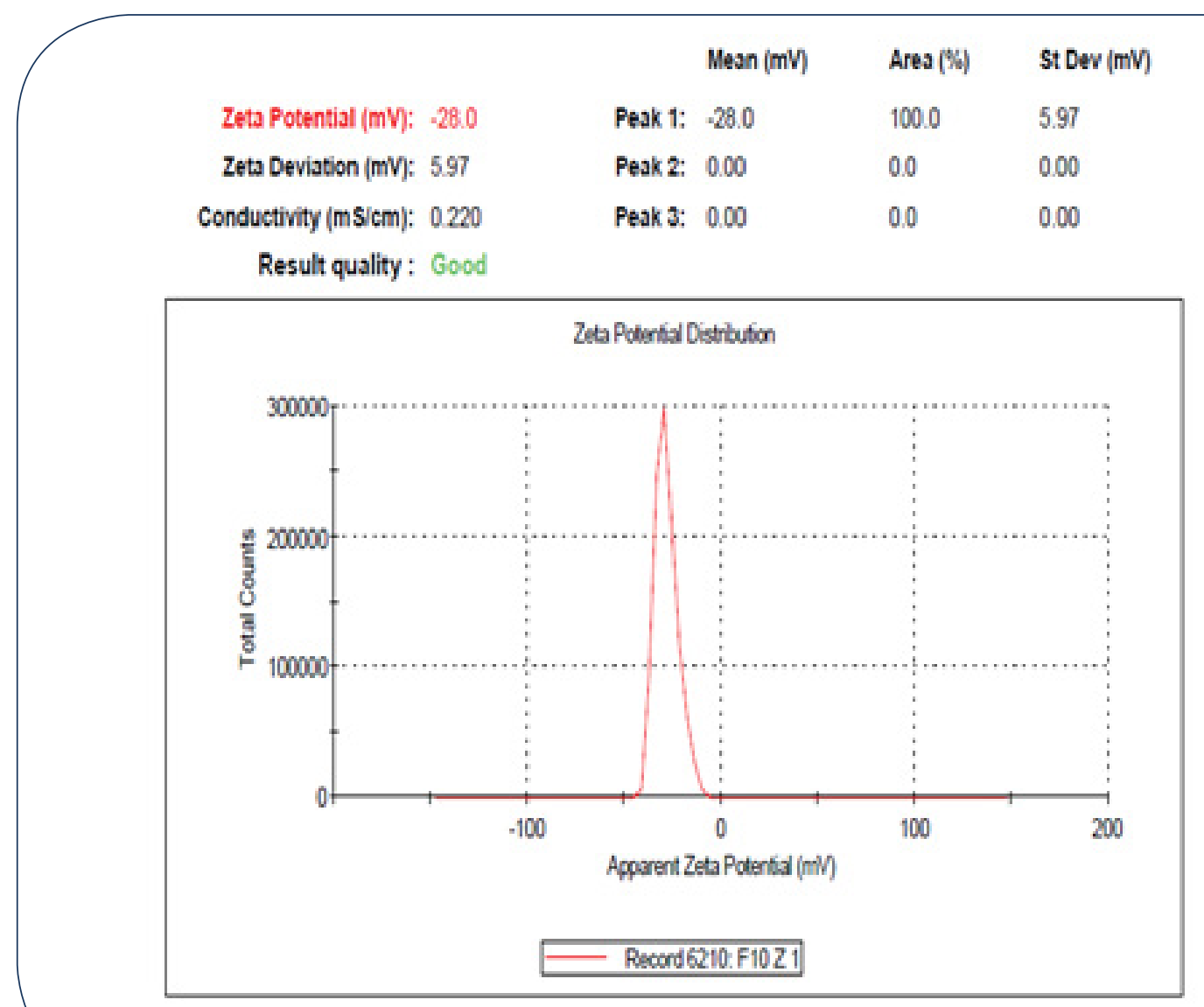

Figure 10. Zeta potential distribution of Pterocarpus marsupium silver nanoparticles

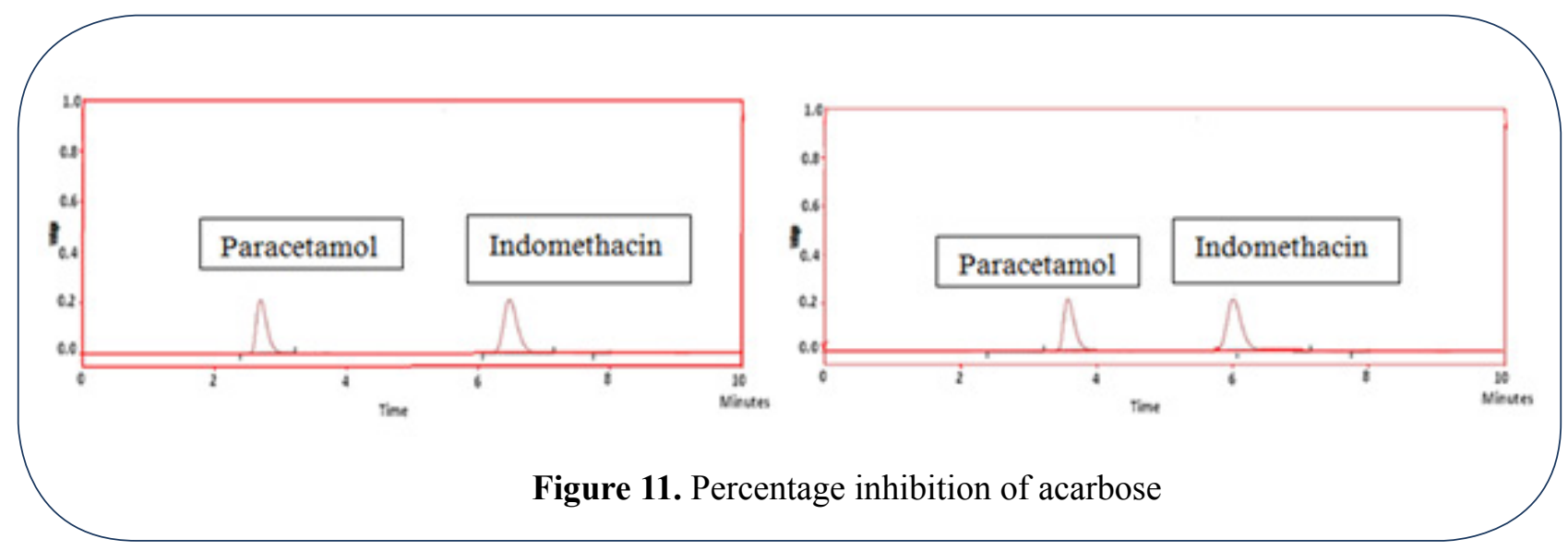




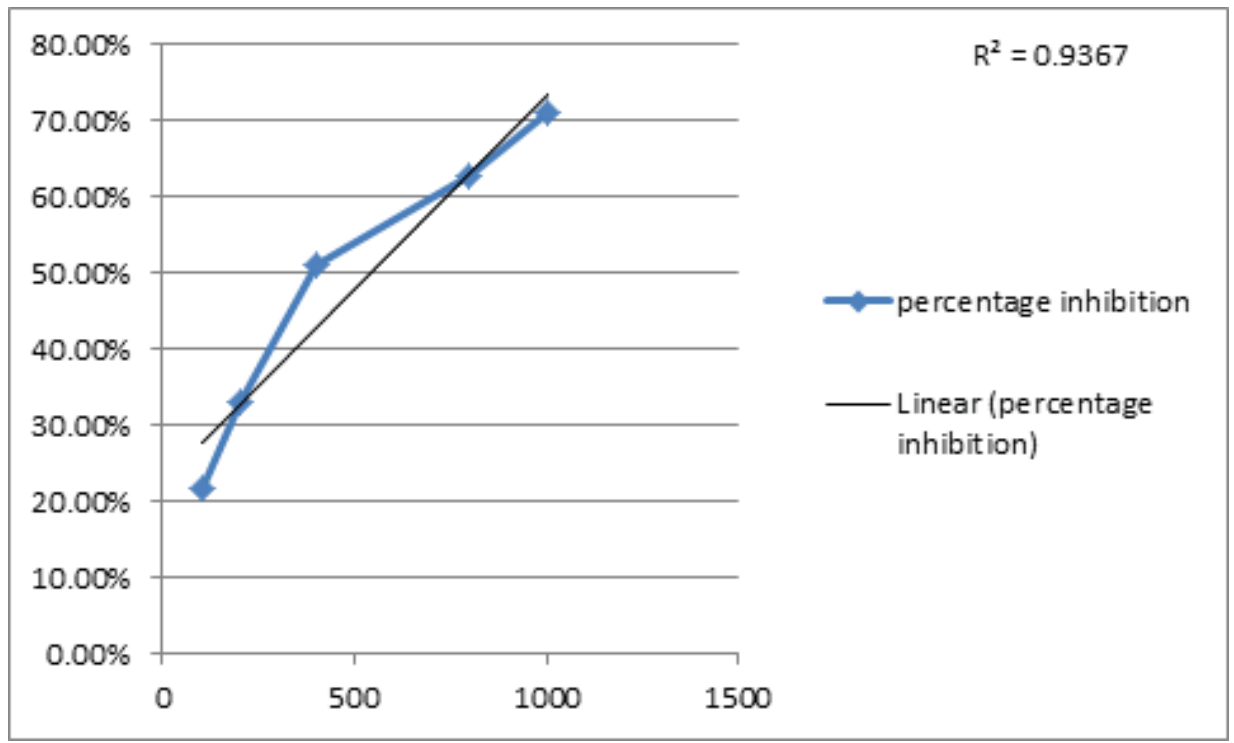

Figure 12. Percentage inhibition of Pterocarpus marsupium silver nanoparticles 